\title{
CARACTERIZAÇÃO FÍSICO-QUÍMICA DA SEMENTE DE UVA DA VARIEDADE CABERNET SAUVIGNON
}

\author{
F. M. OLIVEIRA ${ }^{1}$, G. P. BRUNI ${ }^{1}$, M. M. MORAIS ${ }^{1}$, R. B. SANTOS $^{1}$ e V. T. CREXI $^{1}$ \\ ${ }^{1}$ Universidade Federal do Pampa \\ E-mail para contato: graziellabruni@yahoo.com.br
}

\begin{abstract}
RESUMO - Nos últimos anos a vitivinicultura vem se tornando uma atividade muito importante para a sustentabilidade no Brasil. No país são colhidos cerca de 80.700 ha, destes, aproximadamente 50.000 ha colhidos no Rio Grande do Sul. O processo de fabricação de vinhos gera cerca de 35\% de resíduos (cascas, engaços e sementes), sendo estes geralmente descartados pelas vinícolas, porém do ponto de vista ambiental, a utilização completa de uvas é um aspecto importante na redução de resíduos. Este trabalho teve por objetivo determinar as características físico-químicas das sementes de uva da variedade Cabernet Sauvignon. A caracterização físicoquímica da semente foi realizada através das análises de determinação do diâmetro de partícula, porosidade do leito de partículas, umidade, cinzas, proteínas, lipídios e fibras. Obtiveram-se valores de diâmetro médio e porosidade de $2,91 \mathrm{~mm}$ e 0,47 respectivamente, para semente inteira, para a semente moída encontrou-se valores de diâmetro médio e porosidade de $0,65 \mathrm{~mm}$ e $0,66 \mathrm{~mm}$, respectivamente. Os valores encontrados para umidade, cinzas, proteínas, lipídios e fibras foram de $42,8 \pm 0,1 \%$, $2,79 \pm 0,01 \%, 5,26 \pm 0,15 \%, 12,27 \pm 0,42 \%$ e $36,8 \pm 1,0 \%$, respectivamente. Constatou-se que devido ao alto conteúdo de lipídios e fibras, a semente de uva estudada pode ser utilizada como matéria-prima para extração de óleo, complemento de ração animal e material adsorvente, contribuindo na redução do impacto ambiental gerado pelas vinícolas.
\end{abstract}

\section{INTRODUÇÃO}

Nos últimos anos a vitivinicultura vem se tornando uma atividade muito importante para a sustentabilidade no Brasil. No país são colhidos cerca de $80.700 \mathrm{ha}$, destes, aproximadamente 50.000 ha colhidos no Rio Grande do Sul (Mello, 2011). Dentre as videiras finas cultivadas no Rio Grande do Sul, destaca-se a Cabernet Sauvignon de origem francesa, que passou a ser cultivada em maior escala no Brasil somente a partir da década de 80, tornando-se, assim, uma importante uva para a vinificação no país.

Do ponto de vista ambiental, a utilização completa de uvas é um aspecto importante na redução de rejeitos. O processo de fabricação de vinhos gera cerca de $35 \%$ de resíduos (cascas, engaços e sementes) sendo estes geralmente descartados pelas vinícolas (Freitas, 2007 e Murga et al., 2000). 
Segundo Oliveira (2003) as sementes representam de 2 a $5 \%$ de peso da uva e contém 10 a $20 \%$ de óleo comestível. A semente de uva é composta ainda, por aproximadamente $40 \%$ de fibras, 8 a 11\% de proteínas, $7 \%$ de compostos fenólicos complexos (taninos), açúcares, sais minerais, etc. (Rockenbach, 2012). As sementes são geralmente queimadas e, algumas vezes utilizadas para a alimentação do gado, apesar de serem uma excelente fonte de óleo para o consumo humano. Entretanto, devido ao seu alto conteúdo de fibras esta também pode ser utilizada como material adsorvente (Luque-Rodríguez et al., 2005).

A qualidade do óleo de uva deve-se ao seu elevado nível de ácidos graxos insaturados (cerca de 90\%), particularmente linoléico (C18: 2) e oléico (C18: 1); traços de ácido linolênico (C18: 3) e palmitoléico (C16: 1), além da atividade antioxidante que apresenta devido à presença de vitamina E. Os ácidos graxos insaturados linoléico e linolênico são essenciais para o metabolismo humano devido à ausência de enzimas responsáveis para a sua síntese. Por esta razão, a ingestão dietética diária destes ácidos é obrigatória (Hanganu et. al., 2012). Os métodos tradicionais para a extração de óleo a partir de sementes são a prensagem e a extração por solvente a quente (Adam et al., 2012 e Deli et al., 2011). Ambos os métodos não tratam das partículas isoladas, mas da fase sólida constituída pelo conjunto delas (leito de partículas); sendo assim, uma das características mais importantes, além da caracterização da própria partícula, é o conhecimento da fração do volume de leito não ocupada pelo material sólido, ou seja, a fração de vazios da fase sólida, que é denominada de porosidade, grandeza esta adimensional que influencia na queda de pressão e no escoamento através da fase sólida (Ribeiro, 2002).

Visto que as indústrias vitivinícolas desempenham um importante papel na economia do sul do país e que são geradas quantidades significativas de resíduos, o presente trabalho se propôs a estudar as características físico-químicas das sementes de uva da variedade Cabernet Sauvignon para que estas possam ser utilizadas como matéria prima para outros fins, como por exemplo, a extração de óleo.

\section{METODOLOGIA}

\subsection{Obtenção da matéria-prima}

As amostras utilizadas para a caracterização fisíco-química foram sementes de uva da variedade Cabernet Sauvignon cultivada por uma vinícola da região de Bagé - RS. A Figura 1 ilustra o fluxograma das etapas realizadas para obtenção das sementes de uva. 


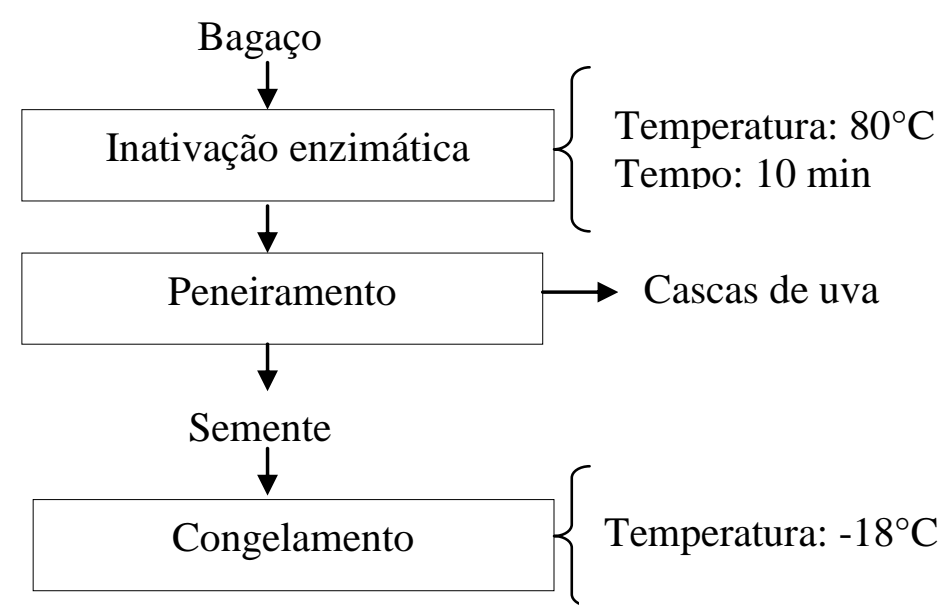

Figura 1 - Fluxograma das etapas realizadas para a obtenção das sementes de uva

O bagaço de uva foi submetido a tratamento térmico em estufa com circulação de ar a $80^{\circ} \mathrm{C}$ por 10 min para inativação enzimática (Rockenbach, 2010); após, realizou-se a etapa de peneiramento do bagaço para a separação das sementes. Para preservar as características fisico-químicas, as amostras foram armazenadas sob congelamento a $-18^{\circ} \mathrm{C}$.

\subsection{Caracterização físico-química}

A caracterização físico-química das sementes obtidas anteriormente foi realizada conforme ilustra a Figura 2.

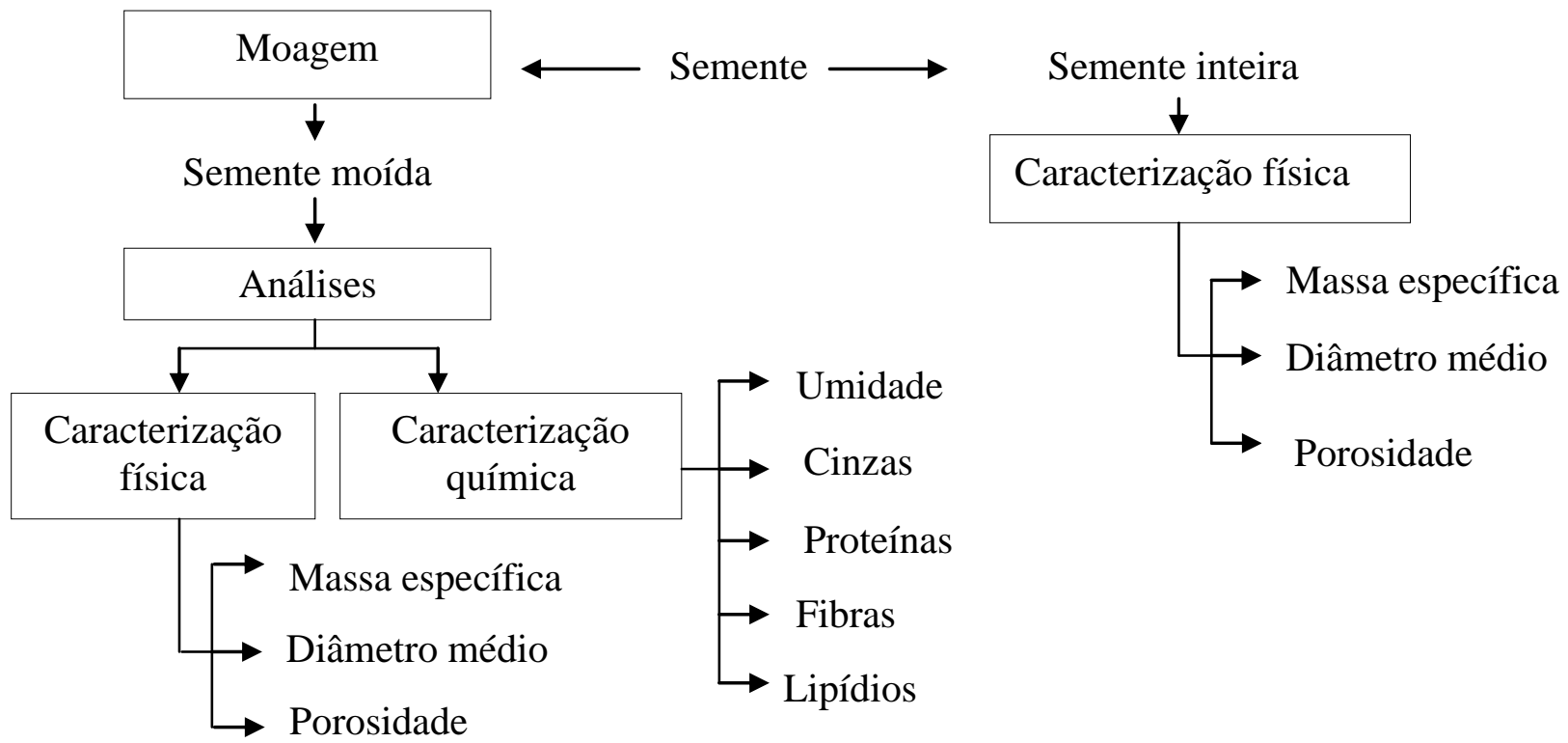

Figura 2 - Fluxograma das etapas do procedimento utilizado para a realização das análises físico-químicas 
A caracterização química foi realizada de acordo com a metodologia proposta pelo Instituto Adolfo Lutz (2008), enquanto que a caracterização física foi conduzida conforme o procedimento descrito por Cresmasco (2012), os quais são apresentados a seguir.

No ensaio de peneiramento, para a determinação do diâmetro médio, montou-se o jogo de peneiras de modo que a malha de maior abertura ficasse acima da malha de menor abertura e no fundo um coletor para as partículas mais finas do material que passaram por todo o conjunto de peneiras. A amostra foi colocada na malha de maior abertura e conduziu-se o jogo de peneiras a um equipamento vibratório, com vibração ajustada no nível 5 do equipamento durante o tempo de 15 min. A partir da massa de partículas retida em cada peneira, o diâmetro médio de Sauter das mesmas foi calculado, utilizando-se a Equação 1.

$D_{p s}=\frac{1}{\sum_{i=1}^{n}\left(\frac{x i}{D i}\right)}$

A porosidade do leito de partículas foi obtida a partir dos ensaios de picnometria gasosa e de proveta, onde foi possível determinar a partir destes procedimentos a massa específica real e aparente, respectivamente (Cremasco, 2012).

A massa específica real das partículas foi determinada em um picnômetro gasoso (Quantachrome Instruments, ultrafoam1000e, modelo UPY-30F). Já no ensaio de proveta, a mesma foi pesada e em seguida preenchida com as partículas sólidas, verificando-se a massa da proveta com a amostra. A massa específica aparente foi determinada utilizando-se a Equação 2.

$\rho_{\text {aparente }}=\frac{m_{\text {amostra }}}{V_{P}}$

Após encontrar as massas específicas real e aparente é possível então determinar a porosidade do leito de partículas através da Equação 3.

$\varepsilon=1-\frac{\rho_{\text {aparente }}}{\rho_{\text {real }}}$

\section{RESULTADOS E DISCUSSÃO}

Os resultados obtidos a partir das análises realizadas para a caracterização química e física das sementes são apresentados a seguir.

\subsection{Caracterização química}

Os resultados da caracterização química da semente de uva podem ser observados na Tabela 1. 
Tabela 1- Resultados obtidos a partir das análises químicas

\begin{tabular}{cc}
\hline Parâmetro & $\begin{array}{c}\text { Cabernet } \\
\text { Sauvignon }(\boldsymbol{\%})\end{array}$ \\
\hline Umidade & $42,8 \pm 0,1$ \\
Cinzas & $2,79 \pm 0,01$ \\
Proteínas & $5.26 \pm 0,15$ \\
Lipídeos & $12,27 \pm 0,42$ \\
Fibras & $36,8 \pm 1,0$ \\
\hline
\end{tabular}

De acordo com os resultados apresentados na Tabela 1 para lipídeos e fibras, foi possível constatar que os valores encontrados estão próximos aos encontrados por Hanganu et al (2012), os quais foram 10 a $20 \%$ de lipídio, e aproximadamente $40 \%$ de fibras segundo Rockenbach (2012), enquanto que o conteúdo de proteínas ficou abaixo do citado (8 a 11\%) por Bail et al (2008), porém os autores não especificaram a variedade de uva estudada. Os resultados apresentados na Tabela 1 sugerem que a semente da uva da variedade Cabernet Sauvignon pode ser utilizada como matéria-prima para extração de óleo, complemento de ração animal e material adsorvente devido aos seus altos teores de lipideos e fibras, respectivamente.

\subsection{Caracterização física}

Os resultados obtidos a partir da caracterização física realizada para as sementes inteiras e moídas apresentam-se na Tabela 2.

Tabela 2 - Resultados obtidos a partir da caracterização física das sementes inteiras e moídas

\begin{tabular}{ccccc}
\hline Amostra & Dps $(\mathbf{m m})$ & $\boldsymbol{\rho}_{\text {real }}\left(\mathbf{g} / \mathbf{c m}^{\mathbf{3}}\right)$ & $\boldsymbol{\rho}_{\text {aparente }}\left(\mathbf{g} / \mathbf{c m}^{\mathbf{3}}\right)$ & $\boldsymbol{\varepsilon}$ \\
\hline Semente inteira & 2,91 & $0,88 \pm 0,01$ & $0,52 \pm 0,02$ & $0,47 \pm 0,02$ \\
Semente moída & 0,65 & $1,25 \pm 0,02$ & $0,44 \pm 0,01$ & $0,66 \pm 0,01$ \\
\hline
\end{tabular}

Através da Equação 1 pôde-se calcular o diâmetro médio de Sauter das partículas, onde o valor encontrado para a semente inteira foi $2,91 \mathrm{~mm}$ e para a semente moída $0,65 \mathrm{~mm}$. Campos (2005), que caracterizou o bagaço de uva, obteve diâmetro médio de partícula de aproximadamente $0,91 \mathrm{~mm}$, este valor mostra-se superior ao diâmetro médio da semente moída devido ao fato do mesmo autor ter caracterizado o bagaço. No processo de moagem, a redução do tamanho de partícula favorece a extração de óleo, pois há um aumento da área superficial, facilitando a transferência de massa durante a extração.

Para a determinação da porosidade, primeiramente foi encontrada a massa específica real e aparente. Estes valores foram aplicados na Equação 3 a fim de obter a porosidade do leito. Campos (2005), determinou a porosidade do leito de partículas de bagaço de uva e este 
apresentou-se semelhante (cerca de 0,63 ) ao encontrado para a semente moída no presente estudo.

Os resultados encontrados demonstram que a moagem da semente aumentou cerca de $23 \%$ a porosidade do leito, o que pode facilitar a extração de óleo por solvente ou prensagem, pois este tenderá a percolar maisfacilmente através do leito de partículas.

\section{CONSIDERAÇÕES FINAIS}

Os valores encontrados para os teores de lipídeos (12,27\%) e fibras $(36,8 \%)$ estão próximos aos encontrados na literatura. O conteúdo de proteínas $(5,26 \%)$ ficou abaixo do listado na literatura enquanto que o valor de umidade foi de $42,8 \%$; estes valores sugerem que a semente de uva da variedade Cabernet Sauvignon pode ser utilizada como matéria-prima para extração de óleo, complemento de ração animal e material adsorvente. Desta maneira pode-se contribuir na redução do impacto ambiental gerado pelas vinícolas. Os valores encontrados de diâmetro médio e porosidade para a semente inteira foram de 2,91mm e 0,47 respectivamente, ; para a semente moída encontraram-se valores de diâmetro médio e porosidade de $0,65 \mathrm{~mm}$ e 0,66 , respectivamente. Assim, a partir da caracterização física observou-se que ocorreu uma redução no tamanho da partícula na semente moída, como já era esperado, pois esta passou por uma etapa de moagem, aumentando assim, a área superficial e também a porosidade do leito, o que pode influenciar positivamente na extração do óleo de semente de uva.

\section{NOMENCLATURA}

\section{Abreviatura}

$\mathrm{D}_{i}$
$\mathrm{D}_{\mathrm{ps}}$
$\varepsilon$
$\rho_{\text {aparente }}$
$\rho_{\text {real }}$
$\mathrm{m}_{\mathrm{amostra}}$
$\mathrm{n}$
$\mathrm{V}_{p}$
$\mathrm{x}_{i}$

\section{Nome}

Diâmetro médio das malhas das peneiras

Diâmetro médio de Sauter

Porosidade

Massa específica aparente da amostra

Massa específica real da amostra

Massa da amostra

Número de peneiras

Volume da proveta

Fração mássica das partículas retida em uma

\section{Unidades \\ [mm] \\ [mm] \\ Admensional \\ [g.cm ${ }^{-3}$ ] \\ [g.cm ${ }^{-3}$ ] \\ [g] \\ Admensional \\ [mL]}

Admensional

perneira 


\section{REFERÊNCIAS}

AOAC - ASSOCIATION OF OFFICIAL ANALYTICAL CHEMISTS. Official methods of analysis of AOAC International. 16 ed. Gaitheersburg: AOAC, 1997.

BAIL, S., STUEBIGER, G., KRIST, S., UNTERWEGER, H., BUCHBAUER, G. (2008). Characterisation of various grape seed oil by volatile compounds, triacylglycerol composition, total phenols and antioxidant capacity. Food Chemistry, 108, p.1122-1132.

BRUNeTto, G. et al. Produção, composição da uva e teores de nitrogênio na folha e no pecíolo em videiras submetidas à adubação nitrogenada. Ciência Rural, Santa Maria, v.38, n.9, p.2622-2625, 2008b.

BRUNETTO, G. Nitrogênio em videira: Recuperação, acumulação e alterações na produtividade e na composição da uva. 2008a. 139f. Tese (Doutorado em Ciência do Solo) Universidade Federal de Santa Maria.

CAMPOS, L. M. A. S. Obtenção de extratos de bagaço de uva cabernet sauvingnon (Vitis vinífera): parâmetros de processo e modelagem matemática. Dissertação (Mestrado em Engenharia de Alimentos). Universidade Federal de Santa Catarina. 2005. 141p.

COTTYN, B.G.; BOUQUE, C.V; AERTS, J.V.; Agriculture and Evironment. 1981, 6, 283294.

DELI, S., FARAH, M.M., TAJUL, A.Y., WAN, N. W.A. (2011). The Effects of physical parameters of the screw press oil expeller on oil yield from Nigella sativa L seeds. International Food Research Journal. p1367-137.

EMBRAPA. Dados da vitivinicultura. Disponível em <http://www.cnpuv.embrapa.br>. Acesso em: 20 jun. 2013.

FREITAS, L. S.; Desenvolvimento de procedimentos de extração do óleo de semente de uva e caracterização química dos compostos extraídos. UFRGS. Porto Alegre, 2007.

HANGANU, A., TOSCASCÃ, M. C., CHIRA, N.A., MAGANU, M., ROSCA, S. (2012). The compositional characterisation of Romaniam grape seed oils using. Food Chemistry, 134, p. 2453-2458.

INSTITUTO ADOLFO LUTZ. Métodos químico e física para análises de alimentos, ed IV, $1^{\mathrm{a}}$ edição digital , p. 1020, São Paulo, 2008.

LUQUE-RODRÍGUEZ J.M., LUQUE DE CASTRO. M.D., PÉREZ-JUAN P. Extraction of fatty acids from grape seed by superheated hexane. Talanta, 2005.

MELLO, L. M. R., Vitinicultura brasileira - Panorama 2010, EMBRAPA UVA E VINHO, Bento Gonçalves, Brasil, 2011.

MINISTÉRIO DA AGRICULTURA, MAPA. Referências bibliográficas de documentos eletrônicos. Disponível em: <http:/http://www.agricultura.gov.br/vegetal/culturas/uva >. Acesso em:21 jun. 2013. 
MURGA, R., RUIZ, R., BETLTRÁN, S., CABEZAS, J.L. (2000). Journal Agriculture Food Chemistry. 48, p. 3408-3412.

OLIVEIRA, G.P.; ECHEVENGUÁ, M.M.; MESSIAS, R.S.; Processo de extração e caracterização do óleo de semente de uva. UFSC. Santa Catarina, 2003.

ORLANDO, T. G.S.; JÚNIOR, M.J.P.; SANTOS, A.O.; HERNADES, J.L.; Comportamento das cultivares de Cabernet Sauvignon e Syrah em diferentes porta-enxertos. Ciencias Agrotécninas. Lavras, 2008.

PASSOS, C. P., SIVA, R. M., SILVA, F. A., COIMBRA, M. A., SILVA, C. M. (2010). Supercritical fluid extraction of grape seed (Vitis vinifera $L$.) oil. Effect of the operating conditions upon oil composition and antioxidant capacity. Chemical Engineering Journal. 160 , p. $634-640$.

RIBEIRO, V. S., SOBRAL, M. C., ALMEIDA, M. M., SILVA, G. F. (2002). Propriedades físicas de produtos agrícolas. Revista Brasileira de Produtos Agroindustriais, Campina Grande, v.4, n.1, p.1-6, 2002.

ROBERTO, S. R. ; YAMASHITA, F.; SATO, A. J.; SANTOS, C.E.; GENTA, W.; Curvas de maturação da uva 'Tannat' (Vitis vinifera L.) para a elaboração de vinho tinto. Londrina, 2004

ROCKENBACH, I. I., JUGFER, E., RITTER, C., SANTIAGO-SCHÜBEL, B., THIELE, B., FETT, R., GALENSA, R. (2012). Characterization of flavan-3-oils in seeds of grape pomace by CE, HPLC-DAD-DMS and LC-ESI-FTICR-MS. Food Research International. 48, p. 848-855.

ROCKENBACH, I. I; SILVA, G. L.; RODRIGUES, E.; KUSKOSKI, E. M.; FETT, R. Influência do solvente no conteúdo total de polifenóis, antocianinas e atividade antioxidante de extratos de bagaço de uva (Vitis vinifera L.) variedades Tannat e Ancelota. Ciência e Tecnologia de Alimentos, 2008.

SINGH, J., BARGALE, P. C. (2000). Development of a small capacity double stage compression screw press for oil expression. Journal of Food Engineering. 43, p. 75-82. 